\title{
The Impact of Environmental Regulations on Green Economic Efficiency - Evidence from Beijing-Tianjin-Hebei Urban Agglomeration
}

\author{
Boya $\mathrm{Li}^{1}$, Xiaoyan $\mathrm{He}^{2 *}$, Zewen $\mathrm{Niu}^{3}$, Jianwei Pan ${ }^{4}$ \\ ${ }^{1}$ School of Economics, Beijing Wuzi University, No. 321 of Fuhe Street, Beijing 101149, China \\ ${ }^{2}$ School of Urban Economics and Public Administration, Capital University of Economics and Business, \\ No. 121 of Huaxiang Zhangjialukou, Beijing 100070, China \\ ${ }^{3}$ School of Labor Economics, Capital University of Economics and Business, No. 121 of Huaxiang Zhangjialukou, \\ Beijing 100070, China \\ ${ }^{4}$ School of Economics, Beijing Wuzi University, No. 321 of Fuhe Street, Beijing 101149, China
}

Received: 16 July 2020

Accepted: 28 November 2020

\begin{abstract}
Environmental regulation is an important factor affecting the green economic efficiency. The purpose of this study is to find out the relationship between environmental regulation and green economic efficiency in Beijing-Tianjin-Hebei urban agglomeration. A framework was constructed in the first to illustrate the necessity of green economic efficiency and explore the mechanism of environmental regulation. Then, we measured the intensity of environmental regulation and green economic efficiency of Beijing-Tianjin-Hebei urban agglomeration through super efficiency SBM model and empirically examined the impact of environmental regulation on green economic efficiency by adopting the panel regression model. The results show that the level of environmental regulation and green economic efficiency in Beijing-Tianjin-Hebei have been constantly improved in 2008-2017. The relationship between environmental regulation and green economic efficiency shows an inverted "U-shaped" curve. So far, the intensity of environmental regulation of all cities in Beijing-Tianjin-Hebei are on the left side of the curve, demonstrating that the enhancement of environmental regulation will promote regional green economic efficiency. Government support has a positive impact on regional green economic efficiency, while regional fixed asset investment has a negative impact. At last, we put
\end{abstract}

*e-mail: hexiaoyan2017@126.com 
forward some suggestions on how to improve environmental regulation and green economic efficiency in Beijing-Tianjin-Hebei urban agglomeration.

Keywords: environmental regulation, green economic efficiency, Beijing-Tianjin-Hebei urban agglomeration, SBM-DEA model

\section{Introduction}

China's economy has achieved a miracle of rapid growth since the reform and opening up in 1978. However, the extensive growth relying on factor investment has brought ecological damage and environmental pollution. Many industries in China used to be high investment and high energy consumption, resulting in high emissions of pollutants, which have caused negative impacts on ecological environment and seriously threatened people's normal life [1]. At present, China is undergoing the process of converting to the stage of high-quality economic development, which requires the coordinated development of economy, society and environment. In 2019, the Fourth Plenary Session of the $19^{\text {th }}$ CPC Central Committee clearly proposed to promote eco-environmental governance, claiming that economic development should be promoted through both green economic development and regional governance.

Beijing-Tianjin-Hebei urban agglomeration is one of the fast-developing area in North China. It includes Beijing, Tianjin and 11 prefecture-level cities in Hebei Province, covering an area of 215,000 square kilometers and accounting for $2.23 \%$ of the total national land area. For a long time, the economic growth mode in BeijingTianjin-Hebei urban agglomeration has been dominated by extensive input of factors that excessively consume the ecological resources, which has brought about water pollution, air pollution and other environmental issues. According to the 2018 China Eco-Environmental Status Bulletin, the overall eco-environmental quality of Beijing-Tianjin-Hebei lags far behind that of the Yangtze River Delta region, a developed urban agglomeration in southeast of China. From the perspective of air quality and water pollution, most cities in Hebei province have always been in the second place in China. In response to the increasingly serious environmental problems, the governments in Beijing, Tianjin and Hebei have actively issued a series of environmental regulations to ensure sustainable development, such as promoting joint prevention of air pollution, improving the quality of water basins, turning farmland to forests and building up green ecological barriers. Although preliminary results have been achieved in the field of regional environmental protection, the contradiction between the fast economic development and the environment protection is still severe at present, facing some problems such as insufficient governing intensity, restricted by the division of local interests and the mismatch between governing cost and benefit. Thus, it is necessary for governments in Beijing-Tianjin-
Hebei urban agglomeration to implement environmental regulations, strengthen environmental governance and manage pollution emissions.

\section{Material and Methods}

\section{Literature Review}

Environmental regulation refers to a kind of binding behavior that governments formulate policies or measures to regulate social production and economic activities that may cause negative externalities [2]. It is generally proposed in academic articles that regional environmental regulation should integrate the power of governments, enterprises and public organizations to promote comprehensive ecological improvement [3-5]. In specific, governments mainly play the leading role in building a coordination mechanism to deploy responsibilities to different governance subjects, while enterprises, non-governmental organizations and the residents participate in the regional environmental regulation activities [5]. The coordination mechanism of regional environmental regulation means applying administrative power such as "multiple compliance and integration" to limit the economic and social functions of land, and to realize the sustainable development of production, life and ecology $[6,7]$. The academic circles have studied the performance of environmental regulation from many aspects such as water source protection, electric power reform and carbon emission, and believed that the political objectives such as restoring the value of ecological service system, protecting ecological resources, improving energy utilization efficiency and reducing greenhouse gas emissions can be achieved through environmental regulations [8-10]. However, such effects are mainly through environmental engineering, such as ecological restoration projects and returning farmland to forests, rather than producing cost and price mechanism.

In view of economic growth, many studies agree that effective environmental regulation can promote the sustainable development of a city, rectify undesirable externalities and stimulate green innovation within the industry [11-13]. The intensity of environmental regulation can comprehensively evaluate the level of environmental pollution restriction from multiple dimensions. Kim (2019) used the panel data of FDI in 120 developing countries from 2000 to 2014, finding out that strict environmental regulations would attract FDI [12]. Bigerna (2019) used two-stage DEA to measure and decompose the total factor productivity of 
the power sector in $19 \mathrm{EU}$ countries from 2006 to 2014, and analyzed the relationship between the production efficiency of the power sector and the strictness of environmental regulation and market supervision [13].

So far, methods regarding measuring the intensity of environmental regulation mainly include three aspects: (1) taking the level of investment on pollutant emissions as the index, such as the proportion of total investment in industrial pollution control to the total output value of enterprises [14]; (2) measuring the removal rate and standard rate of pollutants $[15,16]$; (3) establishing index system by integrating various factors, such as the number of environmental regulations [17], DID analysis [18] and comprehensive index method [19].

Green economic efficiency is a kind of economic efficiency considering resource loss and environmental cost $[20,21]$. As the demand of green space is constantly increasing in modern cities, green economic efficiency has become an indispensable part for urban sustainable development [22, 23]. Green economic efficiency includes two parts: (1) it is to evaluate the utilization efficiency of input factors in the production process and reflects the ability of unit input cost to obtain expected output; (2) it considers undesired output, the economic efficiency value obtained after the loss of resources and environment. So far, the studies about green economic efficiency are mainly carried out from two aspects: one is to discuss the factors influencing the green economic efficiency; the other is to analyze the specific factors affecting the mechanism of green economic efficiency [24-26]. Environmental regulation can stimulate the competitiveness of the enterprises by improving productivity or increasing product value in European manufacturing sectors [27]. Several methods have been adopted to measure the intensity of green economic efficiency, such as the input-output analysis, data envelopment analysis (DEA) and so on. In recent years, SBM models (Slack-Based Model) are frequently applied to estimate the green economic efficiency. Nie and Wen (2015) [28] used SBM model to evaluate the green economic efficiency of cities above the prefecture level in China, claiming that the relationship between the green economic efficiency and economic development presented a "U-shaped" curve.

Studies regarding the relationship between environmental regulation and green economic efficiency mainly focus on the fields such as the overall effects of environmental regulation, the impact of environmental regulation on enterprise behavior, industrial structure adjustment, technological progress and economic growth [29, 30]. The influence mechanism of environmental regulation on green economic efficiency is complex. On the one hand, green economic efficiency takes resources input and unexpected output into account. It not only measures the ability to obtain the expected output in terms of unit input cost, but also incorporates the cost of resources and environmental utilization into the production process, which leads to the uncertainty of the effect of environmental regulation on green economic efficiency. On the other hand, environmental regulation is an important measure for governments to control environmental pollution and ecological deterioration. However, the effects of environmental regulation on green economic efficiency are uncertain [31].

Some scholars believed that environmental regulation is an effective way to control environmental pollution and is playing an indispensable role in improving the level of green economic efficiency [32]. Environmental regulation can promote the diffusion of green economic efficiency through screening effects and technology spillover, and then improve the level of green economic efficiency in local and surrounding areas. From the perspective of harmonious coexistence of human-ecology system, environmental regulation can not only improve the ecological environment, but also eliminate the negative interference of economic and social activities [33]. Wei et al. [34] stated that tax revenue, such as environmental protection tax, sulfur tax and carbon tax, could improve the air quality. However, some scholars argued that environmental regulation may inhibit the development of green economic efficiency. Gray (1987) [35] studied the impact of environmental regulation on enterprises in the 1970s in the United States and found that environmental regulation would reduce the enterprises' production efficiency by $0.44 \%$ per year. Li (2008) [36] stated that the improvement of environmental regulation would force enterprises to attach new target constraints to the original technology level, which would inhibit the technological innovation and have a negative impact on the green economic efficiency. In addition, some studies believed that the impact of environmental regulation on green economic efficiency is non-linear [37, 38].

Based on the above discussion, it can be found that how to balance the economic growth and environmental protection has been an important topic in the field of sustainable development for a long time. There are many achievements in the academic research on environmental regulation and green economic efficiency. Most research mainly focused on the effect of environmental regulation at the industrial-level or regional-level, lacking city-level analysis. Few sources have studied the impact of environmental regulation on green economic efficiency in the region of BeijingTianjin-Hebei urban agglomeration. Since green economic efficiency and environmental regulation are special phenomenon in a specific geographical scope, the relationship between the two may be various from different regions and economic development. The environmental governance of the Beijing-Tianjin-Hebei urban agglomeration has continued for many years, but it is still one of the most severely polluted areas in China. Therefore, it is necessary to quantitatively analyze the intensity of environmental regulation and the governance effect in the Beijing-Tianjin-Hebei in order to drive green economic development. However, the traditional method of measuring economic 
development using GDP volume and economic growth rate is no longer applicable under the global trend of advocating sustainable development. Therefore, this paper will focus on the gap of existing research and address two questions: (1) What is the current level of green economic efficiency of Beijing-TianjinHebei urban agglomeration? (2) Does environmental regulation have an impact on the regional green economic efficiency? If so, how? On the basis of defining the relevant concepts, this study constructs a series of index system to quantitatively measure the current situation of green economic efficiency in Beijing-Tianjin-Hebei urban agglomeration by adopting SBM model and analyze the impact of environmental regulation on green economic efficiency through panel data regression and Tobit regression.

\section{Analytical Framework}

Based on the idea of "governance subject governance object - governance manner", this paper constructs the formation mechanism of environmental regulation and its effects on green economic efficiency (see Fig. 1). Firstly, environmental regulation is an administrative means to deal with the negative externalities of environmental issues. From the perspective of governance subject, under the premise of homo economicus assumption and leaving out environmental justice, enterprises often ignore environmental costs and discharge pollution in order to pursue economic benefits, that is, the negative externalities of economic activities on the local natural environment and the residents' health. This requires the government to intervene in the market failures and become the actual implementation subject of environmental regulation. On the one hand, the intensity of regulation depends on the government's governance ability and governance objectives On the other hand, it depends on the residents' satisfaction to the environment. The higher the degree of environmental pollution, the stronger the willingness of residents to carry out environmental governance. When their satisfaction declines, they will supervise the government's intervention activities and enterprise's emission behavior through petitions and reports. Secondly, green economic efficiency is the result of coupling the economic and social development with the optimization of environmental quality. To realize green economic efficiency not only need to consider the expected output per unit input cost, but also the environmental cost in the producing process. Without considering the environmental cost, the economic behaviors will over-utilize, consume and discharge the production factors from natural environment, resulting in the negative externalities of economic activities. However, when taking the environmental constraint cost into account, they will reduce the pollution emissions through the green utilization of resources to achieve the improvement and optimization of environmental quality. Thirdly, environmental regulation is an effective way to internalize environmental costs and realize green economic efficiency. According to the relevant study, the key to control the negative externalities caused by economic behavior is to internalize the environmental cost [39]. By setting emission targets, formulating administrative regulations and levying environmental taxes, the government has forced enterprises to carry out technological innovation to reach the emission standard and promote the adjustment and upgrading of industrial structure, and finally achieved the goal of green economic growth under the background of pollution reduction and realized the coordinated development of economic society and ecological environment.

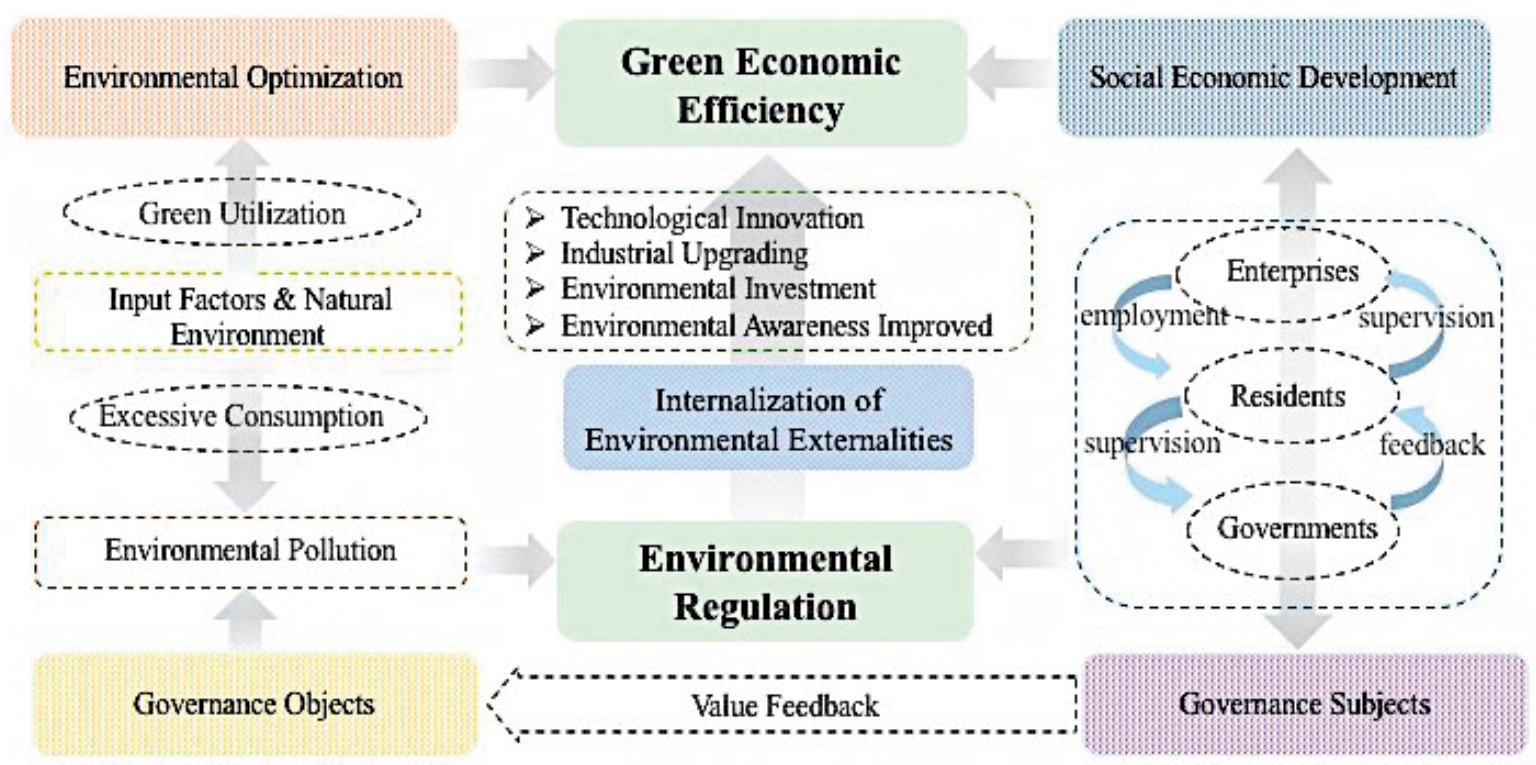

Fig. 1. Governance Model of Regional Social-Economic-Environmental Development. 
Table 1. Index System of Environmental Regulation Intensity in Beijing-Tianjin-Hebei urban agglomeration.

\begin{tabular}{|c|c|c|c|}
\hline \multirow{2}{*}{ Indicator index } & Classification & Index Composition & $\begin{array}{c}\text { Weight mean } \\
\text { value }\end{array}$ \\
\hline \multirow{2}{*}{$\begin{array}{c}\text { Environment } \\
\text { Regulation }\end{array}$} & Exhaust Gas Treatment & Industrial sulfur dioxide removal rate (\%) & 0.3331 \\
\cline { 2 - 4 } & Solid waste treatment & Industrial smoke (dust) removal rate (\%) & 0.3397 \\
\cline { 2 - 4 } & Comprehensive utilization rate of industrial solid waste (\%) & 0.3272 \\
\hline
\end{tabular}

Considering the development situation of BeijingTianjin-Hebei urban agglomeration, we believe environmental regulation the most effective and appropriate manner in promoting green economic development in this region. The effects of environmental regulation on green economic efficiency are reflected in its impact on the producing behavior of enterprises. From the perspective of positive impact, environmental regulation can improve the resource utilization efficiency and increase productivities. The regional industrial structure will be upgraded and optimized and the level of regional green economic efficiency will be improved. From the perspective of negative impact, environmental regulation increases the cost of enterprises in pollution treatment, leading to an overall increase in the producing cost and transaction cost. However, the potential benefits will arouse the enterprise' innovation awareness to make efforts in scientific and technical development. As a result, the production efficiency and the relative competitiveness of enterprises will be improved. Such improvements in efficiency will increase the profits, thereby offsetting the cost caused by environmental regulation. To sum up, the impacts of environmental regulation on green economic efficiency are complex. Different regions give different performance in productivity, profitability and technological innovation. The following sections of this study will analyze the intensity of environmental regulation and green economic efficiency in BeijingTianjin-Hebei urban agglomeration and empirically evaluate the impacts of environmental regulation on green economic efficiency.

\section{Construction of Index System of Environmental Regulation}

There are several types of environmental regulation, such as government-led, market-incentive, informal environmental regulation and so on. Governmentled environmental regulation is that governments formulate laws or regulations to force social members to comply with administrative orders, such as technical standards and performance standards [40]. Marketled environmental regulation is that governments influence the enterprises' pollution discharge through environmental tax, emission trading, etc. to achieve the purpose of environmental regulation. Informal environmental regulation refers to the public awareness of environmental protection. Considering the theoretical analysis above and the data availability, this study selects comprehensive index method to measure the intensity of environmental regulation. Since regional environmental regulation consists of a multi-agent cooperation mechanism, such as air pollution collaborative governance, watershed ecological compensation, and intergovernmental compensation, etc., we take the industrial sulfur dioxide removal rate, the industrial smoke (dust) removal rate and the comprehensive utilization rate of general industrial solid waste as the main observation index (see Table 1) and apply entropy method to reflect the intensity of environmental regulation. The specific steps are as follows (see Formula 1-6):

$$
\begin{gathered}
x_{i j}^{\prime}=\frac{x_{i j}-\min \left\{x_{j}\right\}}{\max \left\{x_{j}\right\}-\min \left\{x_{j}\right\}} \\
x_{i j}^{\prime}=\frac{\max \left\{x_{j}\right\}-x_{i j}}{\max \left\{x_{j}\right\}-\min \left\{x_{j}\right\}} \\
y_{i j}=\frac{x_{i j}^{\prime}}{\sum_{i=1}^{m} x_{i j}^{\prime}} \\
e_{j}=-k \sum_{i=1}^{m}\left(y_{i j} \times \ln y_{i j}\right) \\
d_{j}=1-e_{j} \\
w_{j}=\frac{d_{j}}{\sum_{j=1}^{n} d_{j}} \\
s_{i j}=\sum_{j=1}^{n} w_{j} \times x_{i j}^{\prime}
\end{gathered}
$$

...where, $x_{i j}$ represents the value of the index $\mathrm{j}$ in year $\mathrm{i}$, $\min \left\{x_{j}\right\}$ and $\max \left\{x_{j}\right\}$ are the minimum and maximum values of index $\mathrm{j}$ in all years. $k=1 / \mathrm{lnm}$, where $m$ represents the number of cities and $n$ represents the number of indexes. In the first, all the data is classified into positive indicator and negative indicator after data standardization (see Formula 1). Then, Formula 2 is applied to calculate the ratio of index value of index $j$ in year i. Formula 3-5 are applied to estimate the index information entropy, information entropy redundancy and index weight, respectively. At last, we get the comprehensive value of environmental regulation by Formula 6. 
Table 2. Green Economic Efficiency Index System of Beijing-Tianjin-Hebei.

\begin{tabular}{|c|c|c|}
\hline Index & Classification & Index Composition \\
\hline \multirow{4}{*}{ Input indicators } & Labor force input & Number of employees at the end of the period (person) \\
\hline & Capital investment & Fixed asset investment of the whole society (converted into stock) $(10,000 \mathrm{CNY})$ \\
\hline & Land input & Urban built-up area $\left(\mathrm{km}^{2}\right)$ \\
\hline & Energy input & Electricity consumption of the whole society $(10000 \mathrm{KWH})$ \\
\hline \multirow{4}{*}{ Output indicators } & Desirable output & Gross Domestic Product (10,000 CNY) \\
\hline & \multirow{3}{*}{ Undesirable output } & Industrial wastewater discharge (10,000 tons) \\
\hline & & Industrial sulfur dioxide emissions (ton) \\
\hline & & Industrial smoke (powder) dust emission (ton) \\
\hline
\end{tabular}

\section{Estimate of Green Economic Efficiency}

\section{Evaluation Index Selection}

The core aspect of green economic efficiency is to meet the requirements of environmental protection and sustainable resources consumption so that the utilization of natural resources could promote economic development simultaneously [41]. According to the previous research, we construct an index system of green economic efficiency from the aspects of input and output (see Table 2). Input indicators include labor, capital, land and energy, which mainly reflect the degree of economic growth through the number of factor inputs. In this study, the number of employees at the end of the period, the amount of fixed asset investment in the whole society, the area of urban built-up area and the electricity consumption of the whole society are selected to represent input indicators. We use the perpetual inventory method to convert the total investment in fixed assets into capital stock. The specific calculation formulas are as follows:

$$
\begin{gathered}
\mathrm{K}_{\mathrm{t}}=\mathrm{K}_{\mathrm{t}-1}(1-\delta)+\mathrm{I}_{\mathrm{t}} \\
\mathrm{K}_{0}=\frac{\mathrm{I}_{0}}{\mathrm{~g}_{\mathrm{i}}+\delta}
\end{gathered}
$$

...where $\mathrm{K}_{\mathrm{t}}$ and $\mathrm{K}_{\mathrm{t}-1}$ represents the capital stock in period $t$ and $t-1$, respectively. $\delta$ represents the capital depreciation rate. $I_{t}$ represents the actual investment in fixed assets of the whole society in period $t . \mathrm{K}_{0}$ is the capital stock of the base period, and $g_{i}$ is the average growth rate of the actual investment in fixed assets of the whole society in a certain period. Drawing on the practice of Zhang et al (2004) [42] for reference, the depreciation rate $\delta$ is set at $9.6 \%$.

Output indicators include desirable output and undesirable output. Among them, the gross domestic product of " $2+11$ " cities in Beijing-Tianjin-Hebei urban agglomeration are used to represent the desirable output, and the amount of industrial wastewater, industrial sulfur dioxide and industrial smoke (dust) emissions are undesirable output. There is a negative correlation between undesirable output and green economic efficiency.

\section{Super Efficiency SBM Model with Undesirable Output}

Green economic efficiency takes resource utilization and environmental loss into production process to obtain efficiency values. Data envelopment analysis (DEA) model is widely used to evaluate economic efficiency, which can deal with the total factor productivity analysis of input and output factors simultaneously. However, the traditional DEA model with radial distance or directional distance function ignores the relaxation of variables. In recent years, SBM (Slacks-Based Measure) model has been widely used in the calculation of green economic efficiency. Nevertheless, the results of traditional SBM are in the range of $0-1$, making it impossible to distinguish and rank the effective units whose green economic efficiency value are equal to 1 . Then, Tone (2002) [43] proposed the super efficiency SBM model, allowing the value of decision-making unit (DMU) to be greater than 1 , which has effectively solved the defects of the traditional SBM model. In this study, we adopt super efficiency SBM model considering undesirable outputs to measure the green economic efficiency of " $2+11$ " cities in Beijing-Tianjin-Hebei urban agglomeration in 2008-2017. The formulas are as follows (see formula $9-10)$ :

$$
\rho^{*}=\min \rho=\min \frac{1+\frac{1}{n} \cdot \sum_{i=1}^{n} s_{i}^{-} / x_{i k}}{1-\frac{1}{s_{1}+s_{2}} \cdot\left(\sum_{r=1}^{s_{1}} \frac{s_{r}^{g^{+}}}{y_{r k}^{g}}+\sum_{t=1}^{s_{2}} \frac{s_{t}^{b^{-}}}{y_{t k}^{b}}\right)}
$$




$$
\text { s.t. }\left\{\begin{array}{l}
x_{i k} \geq \sum_{j=1, j \neq k}^{m} x_{i j} \cdot \lambda_{j}-s_{i}^{-} \\
y_{r b}^{g} \leq \sum_{j=1, j \neq k}^{m} y_{r i} \cdot \lambda_{j}+s_{r}^{g^{+}} \\
y_{t k}^{b} \leq \sum_{j=1, j \neq k}^{m} y_{t j}^{b} \cdot \lambda_{j}-s_{t}^{b^{-}} \\
1-\frac{1}{s_{1}+s_{2}} \cdot\left(\sum_{r=1}^{s_{1}} \frac{s_{r}^{g^{+}}}{y_{r k}^{g}}+\sum_{t=1}^{s_{2}} \frac{s_{t}^{b^{-}}}{y_{t k}^{b}}\right)>0 \\
s^{-}, s^{g^{+}}, s^{b^{-}}, \lambda \geq 0 \\
i=1,2 \cdots n \\
r=1,2 \cdots s_{1} \\
t=1,2 \cdots s_{2} \\
j=1,2 \cdots m
\end{array}\right.
$$

...where $\rho^{*}$ stands for the value of green economic efficiency. $x_{i k}, y_{r k}{ }^{g}$ and $y_{r k}{ }^{b}$ represents the number of inputs, desirable output and undesirable output of the DMU $k$, respectively. The DMU of this research is " $2+11$ " prefecture-level cities in Beijing-Tianjin-Hebei urban agglomeration. $s$ and $\lambda$ represents the slack variable and the weight, respectively. The objective function $\rho$ decreases monotonically with respect of $x_{i k}, y_{r k}{ }^{g}$ and $y_{r k}{ }^{b}$. When $\rho=1$, the DMU is fully valid; when $\rho<1$, the DMU is relatively invalid, that is, there is efficiency loss which can be improved by optimizing the constitute of inputs and outputs.

The results of SBM model include three aspects: comprehensive technical efficiency, pure technical efficiency and scale efficiency. From the perspective of variable returns to scale, the comprehensive technical efficiency $=$ pure technical efficiency $\times$ scale efficiency. Among them, comprehensive technical efficiency is the main index to analyze the operation efficiency of the research object, which is affected by pure technical efficiency and scale efficiency at the same time. Pure technical efficiency emphases on the operation efficiency of research objects from the perspective of technological advances, management level and institutional efficiency, while scale efficiency focuses on imitating the operation efficiency from the difference between the actual scale of input and output and the optimal scale.

\section{Specification of Panel Regression Model}

In order to analyze the influencing factors of green economic efficiency in Beijing-Tianjin-Hebei urban agglomeration, especially whether environmental regulation has significant impact on green economic efficiency, we construct a panel regression model to investigate the relationship between the factors. The equation is constructed as follows:

$$
\begin{gathered}
G E E_{i t}=\beta_{0}+\beta_{1} E R_{i t}+\beta_{2}\left(E R_{i t}\right)^{2}+\beta_{3} \operatorname{Ind}_{i t} \\
+\beta_{4} R D_{i t}+\beta_{5} \operatorname{Inv}_{i t}+\beta_{6} G_{o v}+\mu_{i t}
\end{gathered}
$$

...where $G E E_{i t}$ represents the value of green economic efficiency of region $i$ in year $t . E R_{i t}$ represents the environmental regulation intensity. $\ln d_{i t}, R D_{i t}$, $l n v_{i t}$ and $G o v_{i t}$ are control variables, representing the industrial structure, scientific and technological innovation, fixed assets investment, financial support of region $i$ in year $t$, respectively. $\beta_{0}$ is a constant term, $\beta_{1}-\beta_{6}$ is the regression coefficient of each variable, and $\mu_{i t}$ is the random interference term.

This study takes 13 cities in the Beijing-TianjinHebei urban agglomeration as the research objects and the research time are from 2008 to 2017. The specific explanations of each variable are as follows:

1. Explained variable. Taking the green economic efficiency of each city $G E E_{i t}$ as the explained variable, which is calculated by the super efficiency SBM model with undesirable outputs.

2. Explanatory variables. Taking the environmental regulation intensity $E R_{i t}$ as the core explanatory variable, which is calculated by the index system described in the above section. Since the relationship between the primary term of environmental regulation and green economic efficiency is uncertain, we applied the quadratic term of environmental regulation $\left(E R_{i i}\right)^{2}$ into the model.

3. Control variables. According to the environmental economics theory, we respectively select four control variables. Industrial structure $($ lnd $)$ is represented by the ratio of the added value of the secondary industry to the added value of the tertiary industry, exploring whether industrial structure adjustment and optimization has impact on green economic efficiency. Regional technological innovation $(R D)$ is measured by the proportion of R\&D expenditure in fiscal expenditure of each city. Regional investment level $(\ln v)$ is expressed by the proportion of fixed asset investment in regional GDP, aiming to explain whether the investment on urban construction has impact on regional green economic efficiency. The support of regional governments $(\mathrm{Gov})$ is calculated by the proportion of the regional fiscal expenditure to GDP of each prefecture-level city, indicating the government's financial support to green economic development. The descriptive statistics on the raw data of the influencing factors are shown in Table 3.

\section{Data Sources}

The data of this study comes from China Urban Statistical Yearbook, China Urban Construction Statistical Yearbook and corresponding City Statistical Bulletins in 2008-2017. In specific, the data of urban built-up area comes from China Urban Construction Statistical Yearbook, and the other index data comes from China Urban Statistical Yearbook. To avoid problems of data missing and statistical caliber changing, we use the method of mean value interpolation to supplement the abnormal values or missing values. 
Table 3. Variable Description and Descriptive Statistics.

\begin{tabular}{|c|c|c|c|c|c|c|}
\hline Variables & Symbol & Obs. & Max & Min & Mean & Std. Dev. \\
\hline Green Economic Efficiency & $G E E$ & 130 & 1.306 & 0.394 & 0.799 & 0.311 \\
\hline Environmental Regulation Intensity & $E R$ & 130 & 0.953 & 0.412 & 0.776 & 0.113 \\
\hline Industrial Structure & $\ln$ & 130 & 4.238 & 0.413 & 1.043 & 0.781 \\
\hline Regional Technological Innovation & $R D$ & 130 & 0.013 & 0.000 & 0.002 & 0.003 \\
\hline Regional Investment Level & $\operatorname{lnv}$ & 130 & 5.755 & 0.299 & 0.906 & 0.741 \\
\hline Support of the Government & Gov & 130 & 1.129 & 0.068 & 0.187 & 0.143 \\
\hline
\end{tabular}

\section{Robustness Test}

Since the efficiency value is a censored dependent variable, in this study, we implemented Tobit regression model (Tobin, 1958) [44] to test the results validity. The Tobit regression model is widely adopted in academic circle to overcome the shortage of common method when the dependent variables are partially continuous or partially discrete that may lead to deviation and inconsistency of the parameter estimators [45].

\section{Results and Discussion}

\section{Analysis of the Regional Environmental Regulation}

The results show that the environmental regulation of most cities in Beijing-Tianjin-Hebei urban agglomeration has increased in fluctuation during the study period. We select the score in the year of 2008, 2011, 2014 and 2017 for comparative analysis (see Fig. 2). In 2008, the intensity of environmental regulation in Beijing, Tianjin and southeast Hebei were relatively similar with the index score in the range of 0.75-0.85. Cangzhou had the highest score at 0.89 while Zhangjiakou had the lowest at 0.48 . The intensity of environmental regulation of other cities in Hebei province were in the range of 0.5-0.7. When it came to the year 2011, the intensity of environmental regulation in Tianjin, Shijiazhuang and east Hebei were higher than that of most cities. Beijing, Chengde and Handan were the cities that had the score declined. In 2014, the intensity of environmental regulation in southeast Beijing-Tianjin-Hebei urban agglomeration were highly convergent. In specific, Beijing, Tianjin and cities in southeast Hebei had the index score at over 0.85. Tianjin, Shijiazhuang and Cangzhou were the top three cities with the score at $0.91,0.90$ and 0.89 , respectively. In 2017, the intensity of environmental regulation in most cities saw a small dip probably due to the data inconsistency. Altogether, the intensity of environmental regulation in municipalities and provincial capital cities are relatively high because these cities have better economic conditions and technical support, bringing about the strictness of environmental regulations. Since the Synergetic Development of Beijing-Tianjin-Hebei became a national strategy in 2014, the governments in three regions have actively responded to the national call and made great breakthroughs in joint environmental prevention, having a series of pollution control policies and agreements signed such as "Beijing-Tianjin-Hebei Water Eco-Environmental Governance Cooperation Framework Agreement" and "Beijing-Tianjin-Hebei regional Environmental Protection Cooperation Agreement". To a certain extent, this has effectively promoted the important role of the governments and continuously strengthened the intensity of environmental regulation.

The intensity of environmental regulation in each city of Beijing-Tianjin-Hebei urban agglomeration has been continuously increased from 2008 to 2017, which indicated that the response mechanism of environmental policies has been gradually improved. Judging from the regional differences of the subindicators, the industrial smoke and dust removal rate of each city maintained at a high range of more than $95 \%$. The comprehensive utilization rate of general industrial solid wastes in most cities presented a state of "V-shaped" fluctuation, where Tianjin, Shijiazhuang, Cangzhou and Langfang maintained at high regulatory level and Chengde and Zhangjiakou were at low level. For instance, the utilization rate of industrial solid wastes in Langfang decreased from 0.99 in 2008 to 0.73 in 2014 and gradually returned to 0.93 in 2017. Chengde had the utilization rate of industrial solid wastes at 0.31 in 2008, which has dropped to 0.04 in 2014 and rose to 0.24 in 2017. In contrast, the sulfur dioxide removal rate presented an inverted "V-shaped" change, such as Zhangjiakou and Chengde, whose sulfur dioxide removal rate has been doubled from 2008 to 2014 and decreased from 2014 to 2017. Such changes of different indicators led to the "convergence with fluctuation" of the comprehensive index of environmental regulation (see Fig. 3).

The coordinated environmental governance on air pollution has achieved remarkable results. Since the implementation of the regulation named "Three-year Action Plan to Win the Blue Sky", the Ministry of Ecology and Environment has set up a leading group to control air pollution in Beijing-Tianjin-Hebei and 


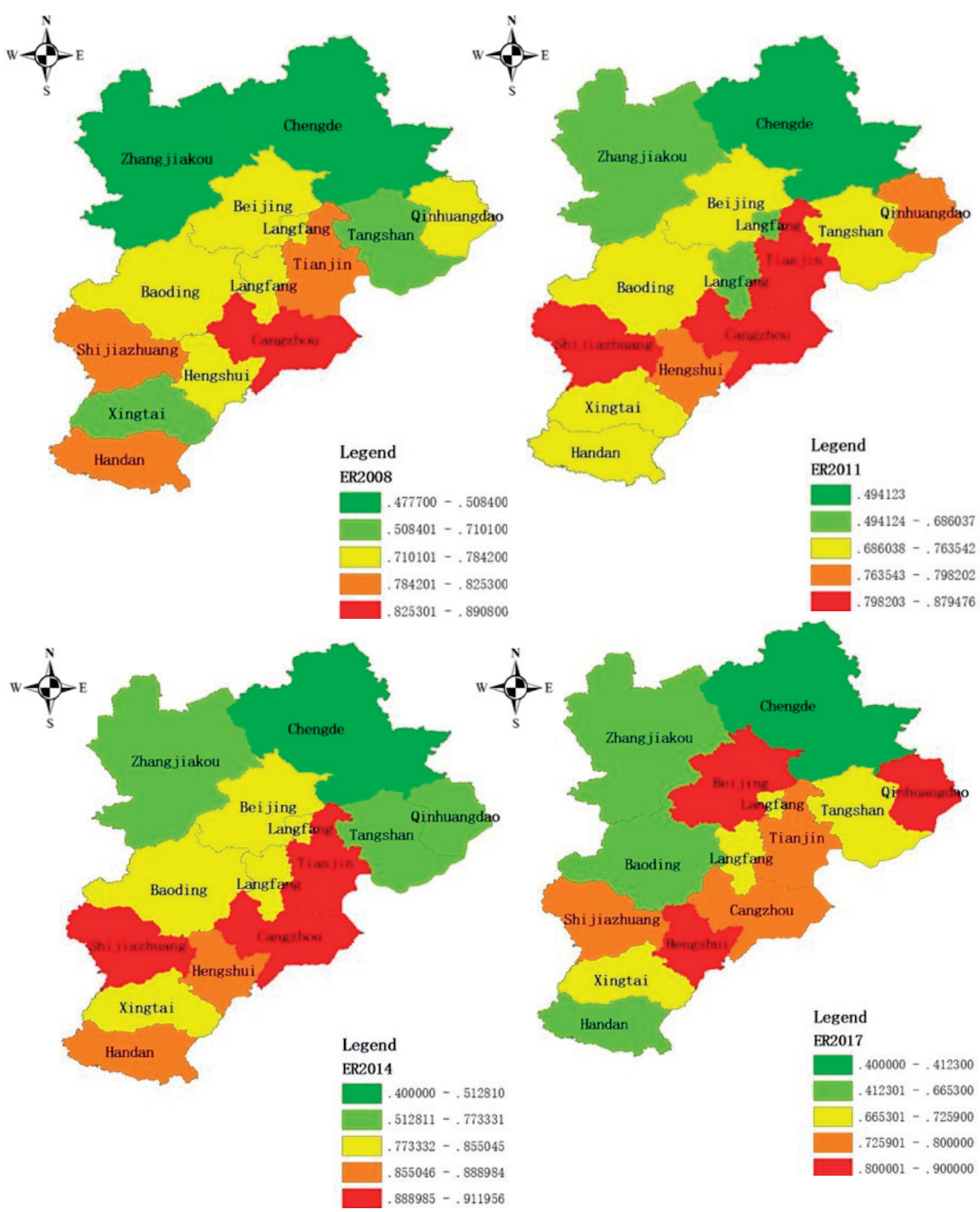

Fig. 2. The Intensity of Environmental Regulation in Beijing-Tianjin-Hebei urban agglomeration (2008, 2011, 2014 and 2017$).$

surrounding areas. In October 2018, a regulation in terms of air pollutant emission limits was launched. As a result, the average annual air quality days in 2018 in Beijing-Tianjin-Hebei urban agglomeration were $50.5 \%$, showing an increase of $1.2 \%$ over 2017 . The concentration of PM2.5 and sulfur dioxide was $60 \mu \mathrm{g} / \mathrm{m}^{3}$ and $20 \mu \mathrm{g} / \mathrm{m}^{3}$, respectively, $11.8 \%$ and $31 \%$ lower than that in 2017. In particular, the concentration of PM2.5 and sulfur dioxide in Beijing was $51 \mu \mathrm{g} / \mathrm{m}^{3}$ and $6 \mu \mathrm{g} / \mathrm{m}^{3}$, respectively, which has decreased by $12.1 \%$ and $25 \%$ compared to 2017 .

The effects of ecological conservation and restoration have also achieved good results. As important ecological conservation areas, Zhangjiakou and Chengde have undertaken the important task of building the demonstration area for ecological restoration. At present, the overall planning of the
Ministry of Ecology and Environment in BeijingTianjin-Hebei urban agglomeration has preliminarily determined the control line for ecological protection. In 2016-2018, Zhangjiakou has made great effort to enhance the intensity of afforestation, completed 10.53 million acres of forests and achieved an afforestation rate of $50 \%$. The forest coverage rate in Zhangjiakou is expected to increase to more than $50 \%$ in 2022 , which will vigorously provide the proportion of mixed forests to improve regional forest quality. In terms of energy saving and emission reduction, a total of 62,000 polluting enterprises were closed down in 2017, and the consumption of bulk coal was reduced by about 10 million tons. The price policy of clean heating resources was implemented and the regulation of industrial off-peak production was applied during heating season in order to reduce energy consumption. Moreover, the 

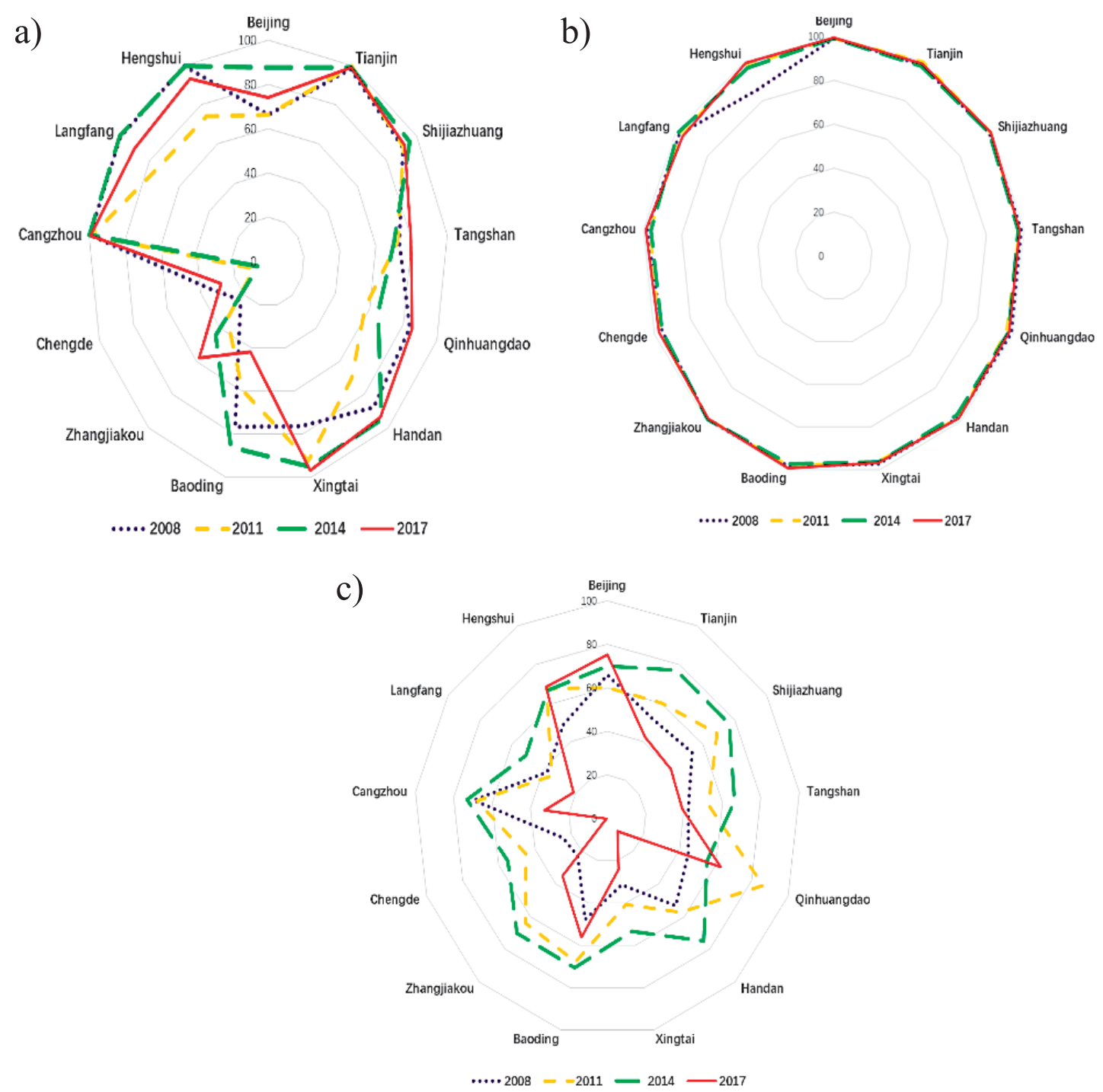

Fig. 3. The utilization rate of a) general industrial solid wastes (\%); b) industrial smoke and dust removal (\%); c) sulfur dioxide removal (\%) in Beijing Tianjin-Hebei urban agglomeration.

clean energy substitution task of replacing coal with gas and electricity was done. The coal collection and distribution ports in Tianjin and Hebei have all turned into railway transportation.

Regarding the construction of collaborative mechanisms, the Atmospheric Environmental Management Agency was found in 2017 and a regulation named Ministry of Ecology and Environment has been launched, aiming to promote the watershed eco-environmental supervision and marineenvironmental management system in Beijing-TianjinHebei urban agglomeration. A policy regulation named "Afforestation Implementation Plan for Zhangjiakou City and Bashang Area of Chengde City" was issued with the purpose of having 2.095 million acres of afforestation by 2022. The total investment amount for the issue was 3.486 billion CNY, which was borne by the central government and local governments. This kind of project-oriented ecological restoration and "central-local government" compensation mechanism has become an important aspect of regional ecological collaborative governance.

Despite many achievements, there are still some deficiencies in the role of environmental regulation at present. First, the effectiveness of environmental regulation in Beijing-Tianjin-Hebei still lags behind other regions. In terms of atmospheric governance, although the number of days with good air quality in Beijing-Tianjin-Hebei has increased, the proportion of days at the substandard level in 2018 is still close to $50 \%$. In contrast, the average number of days at the substandard level in the Yangtze River Delta region composed 25.9\%. The concentration of PM2.5 and PM10 in the Yangtze River Delta region was $44 \mu \mathrm{g} / \mathrm{m}^{3}$ and $70 \mu \mathrm{g} / \mathrm{m}^{3}$, respectively, far superior to those in Beijing-Tianjin-Hebei urban agglomeration. When comparing the core cities of the two regions, the proportion of fine days in Beijing and Shanghai is $62.2 \%$ and $81.1 \%$, respectively. This shows that the Yangtze River Delta region has better pollution 
reduction and governance capabilities than the Beijing-Tianjin-Hebei urban agglomeration. From the perspective of watershed governance, the percentage of excellent surface water sections across the country has been increased since the implementation of the "Water Pollution Prevention and Control Action Plan". The proportion of Class I-III water bodies and the inferior Class V water bodies has reached $67.9 \%$ and $8.3 \%$ in 2018 , respectively. However, comparing to the water quality of the main river basins in China, the Haihe River Basin, where Beijing-Tianjin-Hebei urban agglomeration is located, ranks at the bottom in the country. This has indicated that the collaborative governance on the issues of cross-region and cross-basin environmental regulation still needs to be strengthened in Beijing-Tianjin-Hebei urban agglomeration.

Additionally, a cross-regional collaborative governance mechanism has not yet been formed in the Beijing-Tianjin-Hebei urban agglomeration. On the one hand, the compensation structure is irrational. At present, the main body of cross-border governance in the Beijing-Tianjin-Hebei urban agglomeration is the central government. The local supportive funds account for little proportion due to the limited financial resources at provincial and municipal levels. As a result, a normalized compensation mechanism has not been formed between different regions, resulting in a lack of effective negotiation between the eco-service beneficial area and the ecological resource protection area. On the other hand, the financial transfer payment is mostly in the form of architectural projects and lacks stable longterm effectiveness. The standard of transfer payment is usually a one-off payment, whereas ecological restoration and conservation is a long-term work. Such ecological compensation and transfer payment would lead to a "better short-term, worse long-term" effect in ecological restoration because a mechanism based on ecological inputs and operating costs has not yet been constructed to determine the compensation standard.

\section{Analysis of Regional Green Economic Efficiency}

Based on the results of super efficiency SBM model, we firstly evaluate the overall score of green economic efficiency, focusing on analyzing its changing trend as time goes by. Then, we illustrate the structure of green economic efficiency of each city, respectively, focusing on the spatial and temporal evolution characteristics from the perspectives of comprehensive technical efficiency, pure technical efficiency and scale efficiency. At last, we analyze the current issues of green economic efficiency from the perspective of the change in returns to scale, aiming to find out the input redundancy and output deficiency of each city.

In general, the changes of green economic efficiency have shown that the region as a whole was moving towards green economic development day by day. From 2008 to 2017, the comprehensive technical efficiency and scale efficiency of Beijing-Tianjin-Hebei urban agglomeration have been improved slightly while the pure technical efficiency showing a downward trend. In particular, the score of comprehensive technical efficiency rose from 0.5697 in 2008 to 0.6246 in 2011 and slightly decreased in 2012-2015. Then, a new upward trend appeared from 2015 to 2017, demonstrating that the green economic development in the region has been running well during 2008-2011 and 2015-2017. The pure technical efficiency reflects technical progress and management level. During 2008-2017, the pure technical efficiency of Beijing-Tianjin-Hebei urban agglomeration was generally greater than 1.19 , increased slightly from 2008 and reached the peak value at 1.2083 in 2012, but showed a downward trend since 2012 until it reached the bottom at 0.1949 in 2017. This illustrated that the level of technological progress and management in BeijingTianjin-Hebei urban agglomeration was relatively high, which, to a certain extent, has promoted the regional green economic development. The scale efficiency mainly reflects the gap between the actual scale of green economic development and the theoretical optimal scale. In 2008-2017, the change of scale efficiency of Beijing-Tianjin-Hebei urban agglomeration was similar with the comprehensive technical efficiency. The value of the scale efficiency has surged from 0.4720 in 2008 to the peak value at 0.5239 in 2009 , and then decreased with fluctuation to the lowest value at 0.4787 in 2015 . Afterwards, it has increased again to 0.5034 in 2017 (see Fig. 4).

The green economic efficiency of " $2+11$ " cities in Beijing-Tianjin-Hebei urban agglomeration has formed a core-peripheral spatial pattern. It can be seen that the average green economic efficiency of the core city Beijing has ranked the first with a value of 1.263 while Tianjin ranked the second with a value of 1.065 . The peripheral cities such as Cangzhou, Tangshan, Langfang, Handan and Hengshui list in the third to seventh place. These seven cities held higher value than the average level of 13 cities (0.751) and we divided them into three groups. Beijing list in the first group since its green economic efficiency was far more than other cities. Tianjin, Cangzhou and Tangshan, whose green economic efficiency was between 1 and 1.1, going to the second group, and the rest cities were in the third group. The average value of green economic efficiency of the other cities were all below 0.75 , meaning their green economic development stayed far behind. Xingtai and Zhangjiakou had the lowest green economic efficiency values, which indicated that there may be irrational input and serious resource waste in these cities (see Fig. 5).

From the perspective of comprehensive technical efficiency, the " $2+11$ " cities in Beijing-Tianjin-Hebei urban agglomeration have exhibited heterogeneous fluctuation in 2008-2017. The comprehensive technical efficiency of Beijing, Tianjin, Cangzhou and Tangshan has always been greater than 1, demonstrating that the level of green economic development in these cities were 

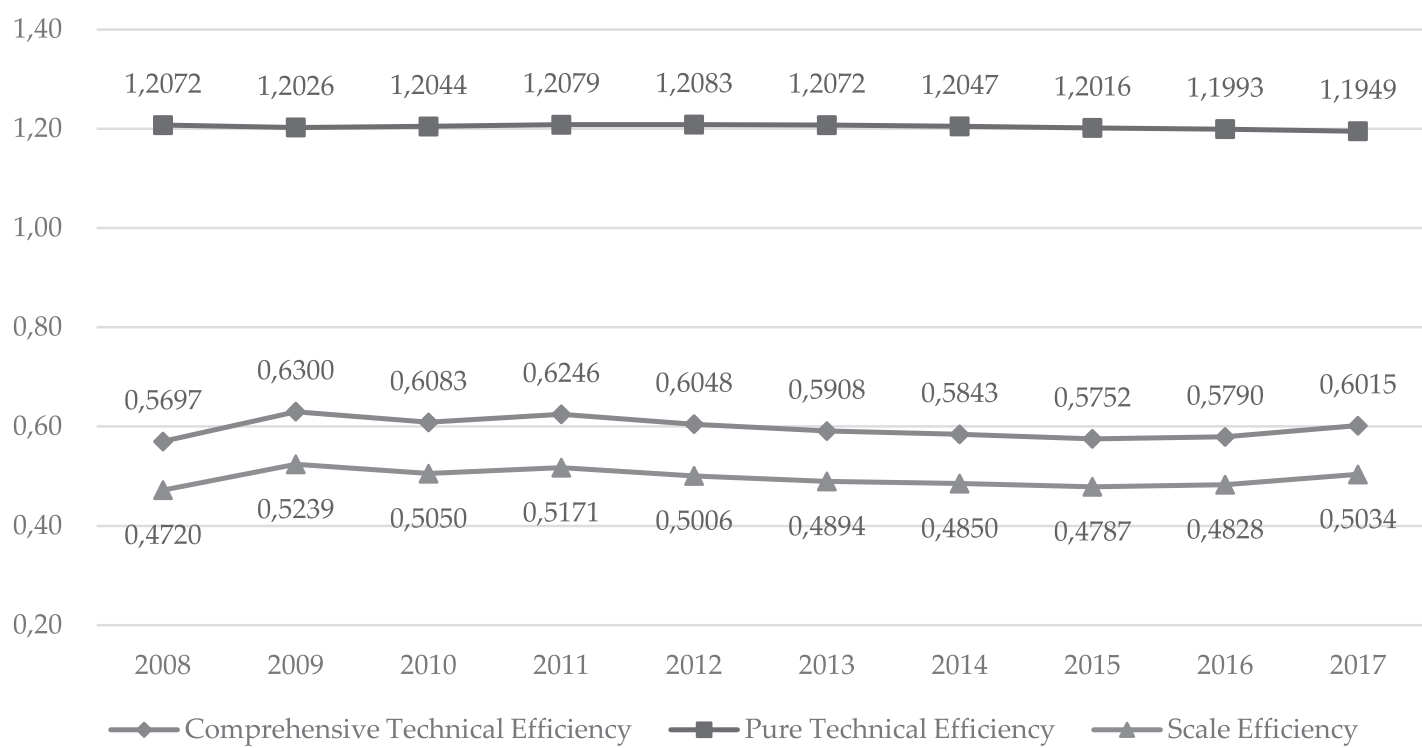

Fig. 4. Green Economic Efficiency Scores of Beijing-Tianjin-Hebei urban agglomeration in 2008-2017.

relatively high and remained in a stable state. Beijing's comprehensive technical efficiency was always in the first place, reflecting its leading role as a core guiding city. The comprehensive technical efficiency values in Langfang, Handan and Hengshui fluctuated in the range of 0.5-1.05 and the values of Shijiazhuang, Chengde, Baoding, Qinhuangdao, Xingtai and Zhangjiakou were in the range of 0.4-0.6 (see Table 4).

From the perspective of pure technical efficiency, the technological progress and management of " $2+11$ " cities in Beijing-Tianjin-Hebei urban agglomeration have significantly improved. From 2008 to 2017, the pure technical efficiency value of most cities have exceeded 1, indicating that the technological progress and management level of each city was constantly improving and the DMUs were effective. In specific, Hengshui, Chengde, Beijing, Cangzhou, Langfang, Tianjin and Tangshan was in an effective state, with technological progress played a significant role in driving green economic development. The pure technical efficiency values of Beijing, Cangzhou, Langfang, Tianjin and Tangshan were stable. Hengshui's pure technical efficiency value increased significantly in 2011-2016, reaching the highest value of 4.612 in 2015, which may be related to the rapid growth of GDP and the decline in the emissions of wastewater, exhaust gas and smoke. The pure technical efficiency value of Chengde remained at about 0.7 in 2008-2010,

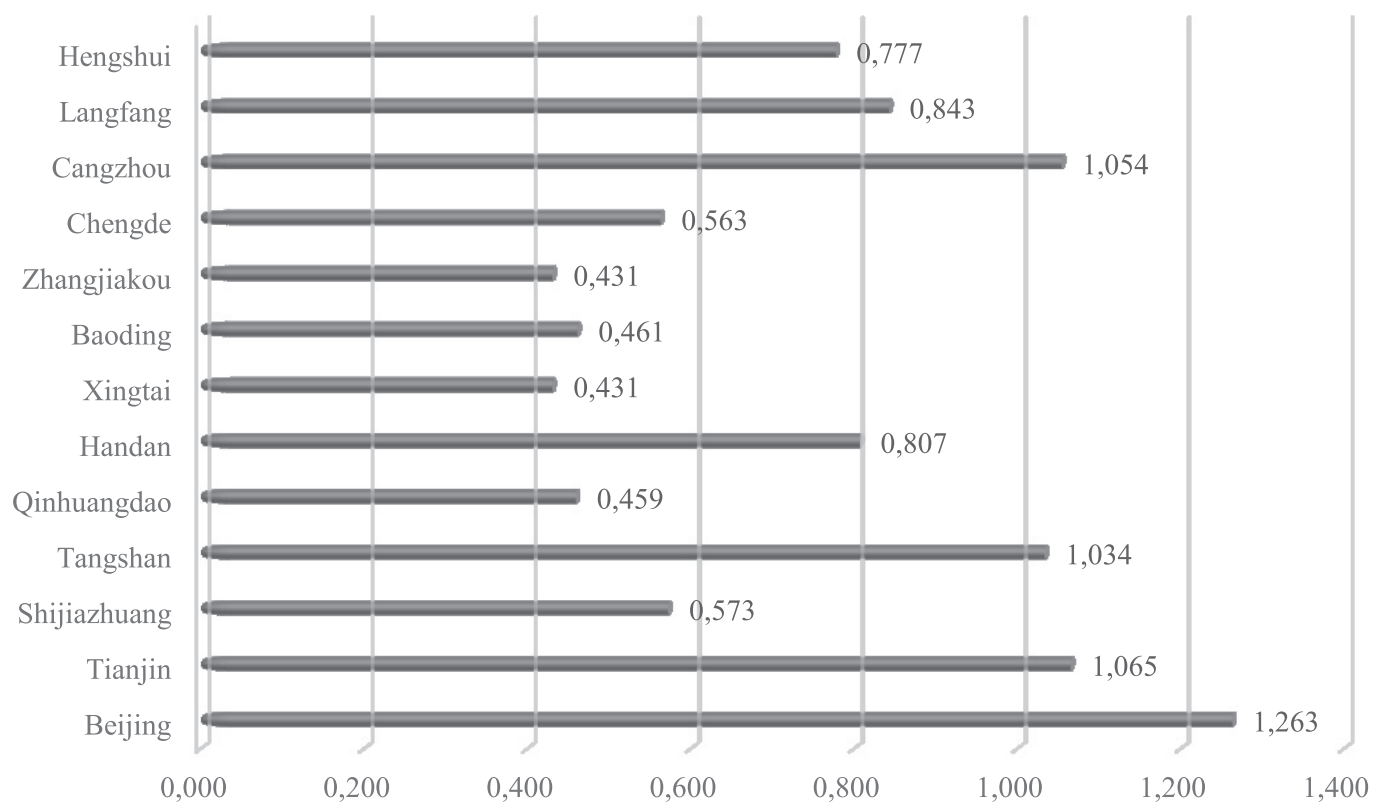

Fig. 5. The Average score of Green Economic Efficiency of each city in Beijing-Tianjin-Hebei urban agglomeration. 
Table 4. The value of Comprehensive Technical Efficiency of each city in Beijing-Tianjin-Hebei Urban Agglomeration in 2008-2017.

\begin{tabular}{|c|c|c|c|c|c|c|c|c|c|c|c|c|}
\hline City & $\mathbf{2 0 0 8}$ & $\mathbf{2 0 0 9}$ & $\mathbf{2 0 1 0}$ & $\mathbf{2 0 1 1}$ & $\mathbf{2 0 1 2}$ & $\mathbf{2 0 1 3}$ & $\mathbf{2 0 1 4}$ & $\mathbf{2 0 1 5}$ & $\mathbf{2 0 1 6}$ & $\mathbf{2 0 1 7}$ & Average Value & Ranking \\
\hline Beijing & 1.242 & 1.236 & 1.241 & 1.251 & 1.249 & 1.255 & 1.270 & 1.289 & 1.292 & 1.306 & 1.263 & 1 \\
\hline Tianjin & 1.011 & 1.049 & 1.038 & 1.085 & 1.087 & 1.087 & 1.078 & 1.089 & 1.061 & 1.069 & 1.065 & 2 \\
\hline Shijiazhuang & 0.529 & 0.547 & 0.508 & 0.613 & 0.594 & 0.590 & 0.527 & 0.537 & 0.554 & 0.731 & 0.573 & 8 \\
\hline Tangshan & 1.048 & 1.028 & 1.018 & 1.046 & 1.039 & 1.039 & 1.036 & 1.028 & 1.022 & 1.033 & 1.034 & 4 \\
\hline Qinhuangdao & 0.542 & 0.506 & 0.478 & 0.505 & 0.454 & 0.421 & 0.412 & 0.404 & 0.413 & 0.469 & 0.459 & 11 \\
\hline Handan & 1.043 & 1.035 & 1.028 & 1.016 & 1.028 & 1.005 & 0.473 & 0.503 & 0.444 & 0.498 & 0.807 & 6 \\
\hline Xingtai & 0.443 & 0.460 & 0.434 & 0.480 & 0.438 & 0.407 & 0.378 & 0.401 & 0.414 & 0.454 & 0.431 & 12 \\
\hline Baoding & 0.492 & 0.511 & 0.481 & 0.510 & 0.468 & 0.460 & 0.432 & 0.388 & 0.405 & 0.468 & 0.461 & 10 \\
\hline Zhangjiakou & 0.412 & 0.439 & 0.432 & 0.456 & 0.445 & 0.438 & 0.423 & 0.432 & 0.420 & 0.412 & 0.431 & 13 \\
\hline Chengde & 0.430 & 0.443 & 0.417 & 1.019 & 1.027 & 0.482 & 0.465 & 0.471 & 0.450 & 0.427 & 0.563 & 9 \\
\hline Cangzhou & 1.088 & 1.105 & 1.097 & 1.052 & 1.041 & 1.042 & 1.026 & 1.026 & 1.021 & 1.045 & 1.054 & 3 \\
\hline Langfang & 1.006 & 0.562 & 0.523 & 1.003 & 0.556 & 0.557 & 1.018 & 1.055 & 1.078 & 1.075 & 0.843 & 5 \\
\hline Hengshui & 1.050 & 1.026 & 1.013 & 1.002 & 0.558 & 0.495 & 0.485 & 0.492 & 0.566 & 1.077 & 0.777 & 7 \\
\hline
\end{tabular}

increased significantly in 2011, then dropped to 0.483 in two consecutive years since 2015. Qinhuangdao's pure technical efficiency value maintained above 1.0 in 2008-2010 and 2016-2017. The pure technical efficiency values of Handan, Shijiazhuang, Xingtai and Baoding were relatively stable and low (see Table 5).

The scale efficiency reflects the gap between the existing scale and the optimal scale of green economic development. The results of the scale efficiency indicate that the green economic development of each city in Beijing-Tianjin-Hebei urban agglomeration has not yet achieved the optimal scale. The scale efficiency of all cities in the region were lower than 1, illustrating that each city has not yet achieved the optimal output or the minimum pollution emissions at the current level of factor input scale. In specific, the overall scale efficiency of Tangshan, Tianjin and Beijing remained above 0.97, which was very close to the optimal scale. Before the year 2014, the scale efficiency value of Handan was above 0.97 . However, it dropped to 0.797 in 2014 but returned to the original level in 2017. Cangzhou had a low scale efficiency value running in the range of 0.6-0.8 in 2008-2010, and it rose to about 0.96 after 2011, showing a "V-shaped" change feature. From 2008

Table 5. The value of Pure Technical Efficiency of each city in Beijing-Tianjin-Hebei Urban Agglomeration in 2008-2017.

\begin{tabular}{|c|c|c|c|c|c|c|c|c|c|c|c|c|}
\hline City & $\mathbf{2 0 0 8}$ & $\mathbf{2 0 0 9}$ & $\mathbf{2 0 1 0}$ & $\mathbf{2 0 1 1}$ & $\mathbf{2 0 1 2}$ & $\mathbf{2 0 1 3}$ & $\mathbf{2 0 1 4}$ & $\mathbf{2 0 1 5}$ & $\mathbf{2 0 1 6}$ & $\mathbf{2 0 1 7}$ & Average Value & Ranking \\
\hline Beijing & 1.247 & 1.250 & 1.247 & 1.267 & 1.262 & 1.274 & 1.310 & 1.483 & 1.305 & 1.369 & 1.301 & 3 \\
\hline Tianjin & 1.061 & 1.077 & 1.092 & 1.089 & 1.094 & 1.097 & 1.097 & 1.100 & 1.105 & 1.103 & 1.082 & 6 \\
\hline Shijiazhuang & 0.617 & 0.590 & 0.544 & 0.639 & 0.615 & 0.594 & 0.601 & 0.605 & 0.599 & 1.001 & 0.640 & 11 \\
\hline Tangshan & 1.067 & 1.046 & 1.035 & 1.064 & 1.054 & 1.047 & 1.043 & 1.033 & 1.025 & 1.037 & 1.045 & 7 \\
\hline Qinhuangdao & 1.584 & 1.629 & 1.465 & 0.663 & 0.649 & 0.659 & 0.680 & 0.620 & 1.014 & 1.031 & 0.998 & 8 \\
\hline Handan & 1.052 & 1.047 & 1.037 & 1.048 & 1.046 & 1.008 & 0.594 & 0.567 & 0.510 & 0.509 & 0.842 & 10 \\
\hline Xingtai & 0.569 & 0.653 & 0.618 & 0.624 & 0.601 & 0.549 & 0.529 & 0.542 & 0.505 & 0.496 & 0.569 & 12 \\
\hline Baoding & 0.521 & 0.527 & 0.507 & 0.619 & 0.574 & 0.585 & 0.573 & 0.533 & 0.511 & 0.494 & 0.544 & 13 \\
\hline Zhangjiakou & 1.007 & 1.029 & 0.760 & 0.712 & 1.017 & 1.027 & 1.026 & 1.030 & 0.609 & 0.511 & 0.873 & 9 \\
\hline Chengde & 0.686 & 0.722 & 0.771 & 1.981 & 2.588 & 2.480 & 2.277 & 2.400 & 1.178 & 0.483 & 1.557 & 2 \\
\hline Cangzhou & 1.369 & 1.820 & 1.512 & 1.098 & 1.090 & 1.099 & 1.094 & 1.094 & 1.046 & 1.048 & 1.229 & 4 \\
\hline Langfang & 1.188 & 1.117 & 1.085 & 1.056 & 1.056 & 1.081 & 1.081 & 1.101 & 1.111 & 1.111 & 1.099 & 5 \\
\hline Hengshui & 1.527 & 1.388 & 1.391 & 3.044 & 2.936 & 2.410 & 2.371 & 4.612 & 2.058 & 1.000 & 3.179 & 1 \\
\hline
\end{tabular}


Table 6. The value of Scale Efficiency of each city in Beijing-Tianjin-Hebei Urban Agglomeration in 2008-2017.

\begin{tabular}{|c|c|c|c|c|c|c|c|c|c|c|c|c|}
\hline City & $\mathbf{2 0 0 8}$ & $\mathbf{2 0 0 9}$ & $\mathbf{2 0 1 0}$ & $\mathbf{2 0 1 1}$ & $\mathbf{2 0 1 2}$ & $\mathbf{2 0 1 3}$ & $\mathbf{2 0 1 4}$ & $\mathbf{2 0 1 5}$ & $\mathbf{2 0 1 6}$ & $\mathbf{2 0 1 7}$ & Average Value & Ranking \\
\hline Beijing & 0.996 & 0.989 & 0.995 & 0.987 & 0.990 & 0.985 & 0.970 & 0.869 & 0.990 & 0.955 & 0.973 & 3 \\
\hline Tianjin & 0.953 & 0.974 & 0.950 & 0.996 & 0.994 & 0.991 & 0.983 & 0.989 & 0.961 & 0.969 & 0.984 & 2 \\
\hline Shijiazhuang & 0.856 & 0.928 & 0.934 & 0.960 & 0.967 & 0.992 & 0.876 & 0.888 & 0.926 & 0.730 & 0.906 & 5 \\
\hline Tangshan & 0.983 & 0.983 & 0.984 & 0.984 & 0.986 & 0.993 & 0.994 & 0.996 & 0.997 & 0.996 & 0.989 & 1 \\
\hline Qinhuangdao & 0.342 & 0.311 & 0.326 & 0.762 & 0.699 & 0.639 & 0.606 & 0.650 & 0.407 & 0.455 & 0.519 & 11 \\
\hline Handan & 0.991 & 0.989 & 0.991 & 0.970 & 0.982 & 0.997 & 0.797 & 0.886 & 0.872 & 0.978 & 0.945 & 4 \\
\hline Xingtai & 0.778 & 0.705 & 0.702 & 0.769 & 0.729 & 0.742 & 0.716 & 0.740 & 0.820 & 0.916 & 0.761 & 9 \\
\hline Baoding & 0.946 & 0.970 & 0.949 & 0.823 & 0.815 & 0.787 & 0.754 & 0.728 & 0.793 & 0.947 & 0.851 & 7 \\
\hline Zhangjiakou & 0.409 & 0.426 & 0.569 & 0.640 & 0.438 & 0.426 & 0.412 & 0.419 & 0.690 & 0.807 & 0.523 & 10 \\
\hline Chengde & 0.627 & 0.613 & 0.540 & 0.514 & 0.397 & 0.195 & 0.204 & 0.196 & 0.382 & 0.884 & 0.455 & 12 \\
\hline Cangzhou & 0.794 & 0.607 & 0.725 & 0.959 & 0.955 & 0.948 & 0.938 & 0.938 & 0.977 & 0.997 & 0.883 & 6 \\
\hline Langfang & 0.847 & 0.503 & 0.482 & 0.949 & 0.527 & 0.515 & 0.942 & 0.958 & 0.970 & 0.967 & 0.766 & 8 \\
\hline Hengshui & 0.688 & 0.740 & 0.728 & 0.329 & 0.190 & 0.205 & 0.205 & 0.107 & 0.051 & 1.077 & 0.431 & 13 \\
\hline
\end{tabular}

to 2010, the scale efficiency value of Baoding remained above 0.9, having experienced a downward trend from 2011 to 2016, and quickly rebounded to 0.947 in 2017. Langfang's scale efficiency value presented a "W-shaped" with two lower inflexion points at 0.482 in 2010 and 0.515 in 2013, respectively. Zhangjiakou, Qinhuangdao, Chengde and Hengshui showed unstable fluctuations (see Table 6).

Comparing the actual level and the optimal target values of inputs and outputs, we find that cities whose comprehensive technical efficiency values are below
1 may have redundant inputs or insufficient output. Beijing, Tianjin, Tangshan and Cangzhou are the cities with high green economic efficiency. The GDP of these cities has far exceeded the current input level, and there is neither redundancy of factor input nor deficiency of undesirable output. From 2008 to 2017, the comprehensive technical efficiency of most cities in Hebei were below 1. Although having increased the returns to scale, these cities have redundant inputs or insufficient output. Baoding and Qinhuangdao had large input redundancy in land resource utilization,

Table 7. The Results of panel Regression.

\begin{tabular}{|c|c|c|c|c|}
\hline & (1) & (2) & (3) & (4) \\
\hline$E R$ & $\begin{array}{c}4.2832 * * \\
(1.9141)\end{array}$ & $\begin{array}{c}4.1723 * * \\
(1.505)\end{array}$ & $\begin{array}{c}4.3469^{* *} \\
(1.5231)\end{array}$ & $\begin{array}{c}4.3607 * * \\
(1.5299)\end{array}$ \\
\hline$E R^{2}$ & $\begin{array}{c}-2.9355^{* *} \\
(1.2967)\end{array}$ & $\begin{array}{c}-2.7023 * * \\
(1.0032)\end{array}$ & $\begin{array}{c}-3.0083^{* *} \\
(1.0042)\end{array}$ & $\begin{array}{c}-3.0023^{* *} \\
(1.0084)\end{array}$ \\
\hline lnd & $\begin{array}{c}0.0608 \\
(0.0680)\end{array}$ & $\begin{array}{c}0.1522 * * \\
(0.0765)\end{array}$ & $\begin{array}{c}0.0651 \\
(0.0818)\end{array}$ & $\begin{array}{c}0.0799 \\
(0.0937)\end{array}$ \\
\hline$R D$ & $\begin{array}{l}8.6580^{*} \\
(5.1263)\end{array}$ & $\begin{array}{c}-0.1939 \\
(12.0416)\end{array}$ & $\begin{array}{c}7.6693 \\
(10.6329)\end{array}$ & $\begin{array}{c}7.8091 \\
(10.6844)\end{array}$ \\
\hline $\ln v$ & $\begin{array}{c}-0.1991 \\
(0.1316)\end{array}$ & $\begin{array}{l}-0.1265^{*} \\
(0.0756)\end{array}$ & $\begin{array}{c}-0.2129^{* *} \\
(0.0722)\end{array}$ & $\begin{array}{c}-0.2111 * * \\
(0.0727)\end{array}$ \\
\hline Gov & $\begin{array}{c}1.1080 \\
(0.7364)\end{array}$ & $\begin{array}{c}0.8642 * * \\
(0.4171)\end{array}$ & $\begin{array}{l}1.1735 * * \\
(0.4032)\end{array}$ & $\begin{array}{l}1.1743 * * \\
(0.4049)\end{array}$ \\
\hline Constant & $\begin{array}{r}-0.8287 \\
(0.658)\end{array}$ & $\begin{array}{l}-0.9461 \\
(0.103)\end{array}$ & $\begin{array}{r}-0.7682 \\
(0.676)\end{array}$ & $\begin{array}{l}3.3323 \\
(0.790)\end{array}$ \\
\hline Time Fixed Effects & No & Yes & No & Yes \\
\hline Entity Fixed Effects & No & No & Yes & Yes \\
\hline Adjusted R-squared & 0.0923 & 0.1210 & 0.8447 & 0.8448 \\
\hline
\end{tabular}

Note: $* * *, * * *$ represents significance level within the level of $10 \%, 5 \%$ and $1 \%$, respectively 
while Handan and Xingtai had redundant input in labor. The input redundancy of electricity consumption in Handan and Qinhuangdao was relatively high, indicating that there was a lot of waste of resources in energy consumption. Such results revealed that these cities had excessive consumption of resources under the current GDP level, so that the combination of input factors should be optimized to improve the efficiency of resource utilization. From the perspective of undesirable output, the redundancy of each index was relatively large. For instance, the redundancy of smoke and dust in Qinhuangdao, Xingtai and Handan has exceeded $60 \%$ and the emissions of sulfur dioxide were more than $70 \%$. This illustrated that the three cities should enhance the regulations in the aspect of pollution control and reduce the amount of pollution emissions. The other cities should improve technology to optimize regional air quality by controlling the sulfur dioxide and smoke dust emissions.

The environmental regulation policies in BeijingTianjin-Hebei region have effectively promoted the regional ecosystem service value and green economic efficiency from the aspects of improving air quality and restoring ecological resources value. In terms of organizational setup, in March 2018, the Ministry of Ecology and Environment was established after the reform of departmental institutions, and the Department of Atmospheric Environment (BeijingTianjin-Hebei and Surrounding Area Atmospheric Environment Administration) was set up to take charge of air pollution control in Beijing-Tianjin-Hebei region. In 2018, the number of days with good air quality in Beijing, Tianjin and Hebei and its surrounding areas increased by $1.2 \%$ compared with 2017 , among which the proportion of excellent days in Beijing was $62.2 \%$, up by $0.3 \%$ compared with 2017 . In the aspect of ecological resource value restoration, the three places have issued a series of environmental collaborative governance regulatory agreements, such as "Threeyear Action Plan for Defending the Blue Sky"," BeijingTianjin-Hebei Regional Environmental Protection First Breakthrough Cooperation Framework Agreement", "Beijing Water Pollution Prevention and Control Work Plan", and "Beijing-Tianjin-Hebei Collaborative Development Forestry Ecology First Breakthrough Framework Agreement", to jointly promote ecological resource restoration and environmental governance. As of 2019, the urban sewage treatment rate in Beijing and Tianjin has reached over $90 \%$, and that in Hebei was $78 \%$. The utilization rate of water resources (water consumption per 10,000 US dollars of GDP) has reached the level of developed countries. The forest coverage rate has reached $44 \%$ in Beijing and $35 \%$ in Hebei, showing an increasing trend year by year. In terms of watershed ecological compensation, Hebei Province and Tianjin signed the Agreement on Horizontal Ecological Compensation for Upstream and Downstream of Luanhe River Diversion into Tianjin, proposing that Hebei and Tianjin jointly contribute to the establishment of water environmental compensation fund for Luanhe River Diversion into Tianjin. By carrying out non-point source pollution control and river dredging projects in Hebei Province, the average annual concentration of water quality in the crossborder sections of Li River and Shahe River entering Tianjin has reached the Class III water quality standard of Environmental Quality Standard for Surface Water (GB 3838-2002). In 2016, 2017 and 2018, the water quality compliance rate reached $65 \%, 80 \%$ and $90 \%$, respectively. In 2017-2018, Hebei Province received the ecological compensation funds from the central government in full for three consecutive years, and the basin compensation mechanism effectively restored the water quality of the basin.

\section{Influential Factor Analysis of Green Economic Efficiency}

Based on the panel data of 13 cities in BeijingTianjin-Hebei urban agglomeration between 2008-2017, the paper makes an in-depth analysis of the impact of environmental regulation on green economic efficiency. The Equation (11) and the variables are applied to construct a panel regression model. The Stata14 software is used to carry out the regression analysis. The specific results are shown in Table 7.

As can be seen from the results of model (4), the significance level of the core explanatory variables, environmental regulation and its quadratic term, are all at $5 \%$. The coefficient of the environmental regulation is 4.3607 and the quadratic term of environmental regulation is -3.0023 , demonstrating the relationship between environmental regulation and green economic efficiency in Beijing-Tianjin-Hebei urban agglomeration presents an inverted "U-shaped" state. Such results illustrate that the effect of environmental regulation on green economic efficiency has an optimal scope. Cities with strong environmental regulation intensity may not necessarily have high green economic efficiency and the government's blindly strengthening environmental regulations may not lead to an increase in green economic efficiency. The maximum green economic efficiency can achieve proximately 1.5834 when the threshold of environmental regulation intensity is at about 0.7262 . Comparing the coefficient results of the explanatory variables and the analysis above, it can be summarized that the current level of environmental regulation of all cities in Beijing-Tianjin-Hebei urban agglomeration are on the left side of the inverted U-shaped curve. Thereby, if we keep on strengthening the the intensity of environmental regulation in most cities in Beijing-Tianjin-Hebei urban agglomeration, the level of green economic efficiency will be further promoted.

The results of control variables show that the regional fixed asset investment has a negative impact on green economic efficiency, with the coefficient of -0.2111 at the level of $5 \%$ significance. The reason for 
Table 8. The Results of Tobit regression.

\begin{tabular}{|c|c|c|c|c|}
\hline Variable & Coefficient & Std. Error & Z value & Prob. \\
\hline$E R$ & $4.276^{* *}$ & 1.455 & 2.94 & 0.003 \\
\hline$E R^{2}$ & $-2.928^{* *}$ & 0.959 & -3.05 & 0.002 \\
\hline $\ln d$ & 0.060 & 0.062 & 0.97 & 0.333 \\
\hline$R D$ & 8.783 & 9.209 & 0.95 & 0.340 \\
\hline $\ln v$ & $-0.197^{* *}$ & 0.069 & -2.85 & 0.004 \\
\hline Gov & $1.101^{* *}$ & 0.386 & 2.85 & 0.004 \\
\hline Constant & -0.828 & 0.558 & -1.48 & 0.138 \\
\hline
\end{tabular}

Note: * ${ }^{* *}, * * *$ represents significance level within the level of $10 \%, 5 \%$ and $1 \%$, respectively

this may be that most cities in Beijing-Tianjin-Hebei urban agglomeration are presently in the stage of rapid urbanization when large amount of investment of fixed assets are undergoing. Excessive increases in the fixed assets may lead to a growing trend of energy consumption so that the impact on green economic efficiency is negative. This is consistent with the findings of most scholars. The government support is a positive factor on the green economic efficiency, with the coefficient of 1.1743 at the level of 5\% significance. This means if the government's investment on pollution prevention increases by $1 \%$, the green economic efficiency will increase by $1.1743 \%$. However, the results of industrial structure and technological innovation are insignificant, demonstrating the impact of these factors are not obvious in Beijing-Tianjin-Hebei urban agglomeration. This is mainly due to the large gap in the economic development and industrial structure between Beijing, Tianjin and Hebei. The high-tech industries such as science and technology R\&D, new energy and environmental protection are developing well in Beijing and Tianjin, while most cities in Hebei Province are undergoing the rapid growth of industrialization. The degree of environmental regulation in Hebei is far behind Beijing and Tianjin. Moreover, the lack of regional cooperation and coordinated governance among the entire Beijing-Tianjin-Hebei urban agglomeration has restricted the effect of technological innovation and industrial structure on the overall green economic efficiency. The result of robustness test has approved the regression results robust and stable over the whole period of analysis (see Table 8).

\section{Conclusions}

The purpose of this study is to find out the nonlinear relationship between environmental regulation and green economic efficiency in Beijing-TianjinHebei urban agglomeration. We firstly construct an analytical framework consists of governance subject, governance object and governance manner to illustrate the necessity of green economic efficiency and explore the mechanism of environmental regulation. Then, we create a series of comprehensive index system to measure the intensity of environmental regulation and use super efficiency SBM model to evaluate the green economic efficiency of " $2+11$ " cities in Beijing-TianjinHebei urban agglomeration. At last, we empirically analyze the impact factors of green economic efficiency by using the panel regression model. The Tobit regression model is employed to test the robustness of the model. The main findings are as follows:

(1) In 2008-2017, the intensity of environmental regulation in the Beijing-Tianjin-Hebei urban agglomeration has been improved constantly and the level of green economic efficiency has been enhanced year by year. The overall green economic efficiency of " $2+11$ " cities presented a "core-periphery" spatial pattern, where the score of Beijing, Tianjin, Tangshan and Cangzhou were significantly better than that of other cities. The pure technical efficiency of each city was relatively high, indicating the comprehensive management and technical innovation have made great progress in the green economic development. However, the scale efficiency of each city remained at low level, which has become the main factor hindering the development of green economy in Beijing-Tianjin-Hebei urban agglomeration. Cities whose comprehensive technical efficiency values are below 1 may have redundant inputs or insufficient output. Hence, most cities in Hebei need to enlarge the scale of production and promote output expansion to obtain the benefits brought by scale economy. The combination of input factors should be optimized to improve the efficiency of resource utilization.

(2) The intensity of environmental governance in Beijing-Tianjin-Hebei urban agglomeration is not effective and a normalized mechanism for coordinated governance across regions has not yet been formed. Currently, the structure of compensation institution in Beijing-Tianjin-Hebei urban agglomeration is simple, the central government is playing the leading role while the financial supports from local governments account for a small part. Moreover, the regional ecological financial transfer lacks a stable and long- 
term mechanism. The unbalanced expenditure structure has made it hard to regulate environmental protection cooperatively.

(3) The relationship between environmental regulation and green economic efficiency in BeijingTianjin-Hebei urban agglomeration shows an inverted "U-shaped" state. This means the green economic efficiency can be optimized when the intensity of environmental regulation is kept within a certain scope. However, if the intensity of environmental regulation exceeds the critical value, the level of green economic efficiency will be inhibited. So far, all the cities in Beijing-Tianjin-Hebei are on the left side of the inverted "U-shaped" curve, indicating there is still a need to enhance environmental regulation in the future. Government's support has a positive impact on green economic efficiency. Therefore, the more the government supports to the field of environmental protection, scientific and technological research, the greater the impact of environmental regulation is on green economic efficiency. Regional fixed asset investment has a negative impact on green economic efficiency because most cities in Beijing-TianjinHebei urban agglomeration are still in the early and middle stages of the industrialization process. The components required by urban construction are mainly from resource consuming and polluting industries. The gap between Hebei and Beijing-Tianjin in economic growth has restricted the technological innovation spillover and industrial adjustment. Moreover, the lack of regional cooperation in Beijing-Tianjin-Hebei urban agglomeration has held back the overall level of green economic efficiency.

Therefore, we suggest that Beijing-Tianjin-Hebei urban agglomeration accelerate the transformation of economic development to build an eco-friendly, livable and harmonious world-class urban agglomeration. This requires the improvement of green economic efficiency and the speed up of energy conservation and emission reduction. Thus, in order to achieve a coordinated development of economy, society and environment, this paper gets the following implications:

(1) It is necessary to construct an effective governance system and expand the space for green economic development. We suggest the districts and counties in Beijing-Tianjin-Hebei urban agglomeration should be taken as the spatial units to build a specific public policy system that coordinates economic, social and environmental development. Also, it is urgent to introduce the regulation of "replacing multiple plans for local development with one master plan" and set up a green development governance system including cross-regional governance subject, spatial planning and governance policies to effectively promote industrial transformation and green economic development.

(2) Market-oriented ecological compensation mechanisms should be improved to strengthen regional collaborative governance. In view of the multiple governance subjects in Beijing-Tianjin-Hebei urban agglomeration, it is suggested that the relevant ministries such as the departments regarding urban construction, environment and transportation from three local governments should work out the spatial control measures for the urban agglomerations under the main governance of Beijing-Tianjin-Hebei Coordinated Development Leading Group. In the short term, it is necessary to set up an ecological compensation mechanism with explicit compensation boundary and capital sharing responsibility between the central and the local governments. In the long term, a normalized compensation mechanism that suits the actual local conditions should be built. Local governments should improve the effectiveness of financial transfer payment according to the principle of "who benefits and who pays", and provide reasonable compensation for the cost generated by the implementation of environmental protection policies. At the same time, the role of the market mechanism should be brought into play in order to clarify the emission rights and pollution compensation standards of each market subject.

(3) Measures that adapt to local conditions should be employed to realize green and low-carbon development. First, it is suggested to build a regional green economic development system and strengthen the integration of emerging industries, such as new energy, new materials, circular economy and high-tech manufacturing industries. Meanwhile, Beijing-Tianjin-Hebei urban agglomeration should establish a more intensive public transport system and digital infrastructure, encouraging the replacement of traditional power with new energy sources to achieve efficient and clean energy utilization. Second, the green economic transformation in line with local conditions should be promoted. In particular, Beijing and Tianjin should improve the effectiveness of environmental governance and develop technologyintensive industries to drive rapid growing of lowcarbon, energy-saving and environmental-friendly industries. In Hebei province, Cangzhou, Langfang and Tangshan should adjust the industrial structure and increase the proportion of low-carbon industries. Political and financial support should be provided to the enterprises in Shijiazhuang, Baoding, Handan, Qinhuangdao, Xingtai and Hengshui to encourage them to carry out scientific and technological innovation. Also, these cities should reduce the level of pollutant emissions and upgrade the traditional industries to realize the overall green economic development. Chengde and Zhangjiakou should speed up the ecological compensation mechanism with Beijing and Tianjin and promote the development of environmental protection industries and high-tech modern industries.

\section{Acknowledgements}

This research was funded by the National Social Science Foundation of China (Grant No. 17ZDA059); Ministry of Education Humanities and Social 
Sciences Planning Fund Project in 2019 (Grant No. 19YJA630074); the Beijing Key Laboratory of Megaregions Sustainable Development Modeling, CUEB (Grant No. MCR2019QN18); Key Technologies R\&D Collaborative Team Construction Program of Beijing Wuzi University in 2020 (Grant No. 2020GG01). The authors would also like to thank the editors and the anonymous reviewers for their constructive comments and advice.

\section{Conflict of Interest}

The authors declare no conflict of interest.

\section{References}

1. SU SH., ZHANG F. Modeling the role of environmental regulations in regional green economy efficiency of China: empirical evidence from super efficiency DEA-Tobit mode. Journal of Environmental Management, 261, 1, 2020.

2. ZHAO Y.M., ZHU F.M., HE L.L. Definition, classification and evolution of environmental regulations. China Population Resources and Environment., 19, 85, 2009.

3. YU M.J. Coordination between central and local governments in ecological governance: an analytical framework. Comparative Economic and Social System, 154, 148, 2011.

4. KONISKY D. Regulatory competition and environmental enforcement: Is there a race to the bottom. American Journal of Political Science. 51 (4), 853, 2007.

5. GENG Y. Study on governance structure of BeijingTianjin-Hebei metropolitan in perspective of new regionalism theory. Urban Development Studies, 22, 15, 2015.

6. LIU Y., WANG J. Theoretical analysis and technical methods of "multiple planning integration" in the rural to urban transition period in China. Progress in Geography, 35, 529, 2016.

7. CUI J. The collaboration of local government on ecological governance: from the prospect of the metropolitan area of Beijing-Tianjin-Hebei. Reform, 235, 138, 2013.

8. BENNETT D.E., GOSNELL H., LURIE S., DUNCAN S. Utility engagement with payments for watershed services in the united states. Ecosystem Services, 8 (06), 56,2014

9. WILLIAMS J.H., KAHRL F. Electricity reform and sustainable development in china. Environmental Research Letters, 3 (04), 357, 2008.

10. LAU L.S., CHOONG CH.K., ENG Y.K. Investigation of the environmental Kuznets curve for carbon emissions in Malaysia: do foreign direct investment and trade matter? [J]. Energy Policy, 68 (05), 490, 2014.

11. NESTA L., VONA F., NOCOLLI F. Environmental policies, product market regulation and innovation in renewable energy. FEEM Working Paper No. 90.2012, Available at SSRN: https://ssrn.com/abstract $=2192441$ or http://dx.doi.org/10.2139/ssrn.2192441.

12. KIM Y.R., DONG E. Do stringent environmental regulations attract foreign direct investment in developing countries? evidence on the "race to the top" from crosscountry panel data[J]. Emerging Markets Finance and Trade, 55 (12), 1, 2019.
13. BIGERNA S., D'ERRICO M.C., POLINOORI P. Environmental and energy efficiency of EU electricity industry: an almost spatial two stages DEA approach[J]. Energy Journal, 40 (01), 29, 2019.

14. BECKER R., HENDERSON V. Effects of air quality regulations on polluting industries. Journal of Political Economy, 108, 379, 2000.

15. SHEN N. Environmental efficiency, industrial heterogeneity and intensity of optimal regulation nonlinear test based on industrial panel-data. China Industrial Economics, 3, 56, 2012.

16. SMARZYNSKA B., WEI S.J. Pollution havens and foreign direct investment: dirty secret or popular myth. The B. E. Journal of Economic Analysis and Policy, Berkeley Electronic Press. 1, 2004

17. ZHANG Z.Y., ZHAO G.Q. FDI, environmental regulation and technological progress - based on the empirical analysis of China's provincial data. The Journal of Quantitative and Technical Economics, 4, 19, 2012.

18. TANG Y., LIANG R.B. TCZ policy and $\mathrm{SO}_{2}$ abatement - an empirical study based on DID. Journal of Shanxi University of Finance and Economics, 34, 9, 2012.

19. FU J.Y., LI L.S. A case study on the environmental regulation, the factor endowment and the international competitiveness in industries. Management World, 10, 87, 2010.

20. ZHAO Y.M., ZHU F.M., HE L.L. Definition, classification and evolution of environmental regulations. China Population Resources and Environment, 6, 85, 2009.

21. QI H.Q., CHEN M. Non-linear characteristics of environmental regulation's impact on China's green economic efficiency. Quantitative Economic Research, 9, 61, 2018.

22. QIAN Z.M., LIU X.CH. Regional differences in China's green economic efficiency and their determinants. China Population Resources and Environment, 7, 104, 2013.

23. YANG ZH.SH., CHENG ZH., LI M.Y., LIN J. Green urbanization: international experiences and implications. Urban and Environmental Studies, 1, 66, 2018.

24. WANG J.T., YUAN Y.W., ZHANG X.ZH., WANG ZH.P. Comprehensive evaluation of the urban green space in the Beijing-Tianjin-Hebei urban agglomeration. Urban and Environmental Studies, 1, 55, 2018.

25. SUN J., LIU W.G., ZHOU Y.D. Opening up, industrial structure and green economic growth - empirical test based on provincial panel data of China. Management World, 6, 172, 2014.

26. ZHANG W.B., DENG L., YIN CH.B. Evaluation of green economy efficiency and analysis of influencing factors in major node cities of the "Belt and Road". Inquiry into Economic Issues, 11, 84-90, 2017.

27. RUBASHKINA Y., GALEOTTI M., VERDOLINI E. Environmental regulation and competitiveness: empirical evidence on the porter hypothesis from European manufacturing sectors. Energy Policy, 35, 288, 2015.

28. NIE Y.L., WEN H.W. Green economic efficiency of Chinese city at the level of municipality or above. China Population Resources and Environment, 25 (S1), 409, 2015.

29. GRAY W.B., SHADBEGIAN R.J. Plant vintage, technology and environment regulation. Journal of Environmental Economics and Management, 46 (3), 384, 2003.

30. YUAN Y.J., XIE, R.H. Research on the effect of environmental regulation on industrial restructuring empirical test based on provincial panel data of China. China Industrial Economic, 8, 57, 2014. 
31. WANG R. The Influence of Environmental Regulation on the Efficiency of China's Regional Green Economy Based on the GMM Model. Polish Journal of Environmental Studies. 29 (3), 2395, 2020.

32. GENG Y.Q., LI Y.Y. Environmental regulation, government subsidies and corporate R\&D investment - empirical analysis based on Chinese manufacturing enterprises. Jianghan Tribune, 7, 11, 2019.

33. CUI X.G., FANG CH.L., ZH Q. Coordination between environmental regulation intensity and urbanization quality: case study of Beijing-Tianjin-Hebei urban agglomeration. Journal of Natural Resources, 33, 563, 2018.

34. WEI W.X., MA X.L., LI P., CHEN Y. Roles of technological progress and tax in regional air pollution control in China. China Population Resources and Environment, 26, 1, 2016.

35. GRAY W.B. The cost of regulation: OSHA, EPA and the Productivity Slow Down. American Economic Review, 77, 998, 1987.

36. LI X.Y. Interactive impact analysis on enterprise innovation and environmental regulation. Science and Management of Science and Technology, 6, 61, 2008.

37. ZHANG Y.H., CHEN J.L., CHENG Y. Study on the influence mechanism of environmental regulation on green economy efficiency in China-empirical analysis based on super efficiency model and spatial panel metering model. Resources and Environment in Yangtze River Basin, 27, 2407, 2018.
38. WANG R., SUN T. Research on the influence of environmental regulation on China's regional green economy efficiency based on super efficiency DEA model. Ecological Economy, 35, 131, 2019.

39. EIDELWEINI F., COLLATTO D.C., RODRIGUES L.H., LACERDA D. P., PIRAN F.S. Internalization of environmental externalities: development of a method for elaborating the statement of economic and environmental results. Journal of Cleaner Production, 170, 1316, 2018.

40. GUO Q. The evolution and enlightenment of environmental regulation in the world. Dongyue Tribune., 30, 140, 2009.

41. SHI M.J., LIU Y.Y. Urban green development: international comparison and problem perspective. Urban Development Research, 20, 140, 2013.

42. ZHANG J., WU G.Y., ZHANG J.P. The estimation of China's provincial capital stock: 1952-2000. Economic Research, 10, 35, 2004.

43. TONE K. A slacks-based measure of super-efficiency in data envelopment analysis. European Journal of Operational Research, 143, 32, 2002.

44. TOBIN J. Estimation of relationships for limited dependent variables. Econometrica, 26, 24-36, 1958.

45. SAGLAM Ü. A two-stage-performance assessment of utility-scale wind farms in Texas using data envelopment analysis and Tobit models. Journal of Cleaner Production, 201 (20), 580, 2018. 
